\title{
ULTRASOUND ASSISTED SYNTHESIS, CHARACTERIZATION AND \\ ELECTROCHEMICAL STUDY OF A TETRADENTATE OXOVANADIUM DIAZOMETHINE COMPLEX.
}

\author{
Moufida Merzougui $^{\mathrm{a}}$, Kamel Ouari ${ }^{\mathrm{a}^{*}}$, Jean Weiss $^{\mathrm{b}}$ \\ ${ }^{a}$ Laboratoire d'Electrochimie, d'Ingénierie Moléculaire et de Catalyse Redox (LEIMCR), Faculté de \\ Technologie, UniversitéFerhat ABBAS Sétif-1, 19000 Sétif, Algérie. \\ ${ }^{b}$ Laboratoire de Chimie des Ligands à Architecture Contrôlée(CLAC),Institut de Chimie UMR 7177 \\ CNRS-Université de Strasbourg, 1 rue Blaise Pascal, 67008 Strasbourg Cedex, France.
}

\section{Abstract}

The oxovanadium(IV) complex "VOL" of a tetradentate Schiff base ligand derived from the condensation of diaminoethane and 2-hydroxy-1-naphthaldehyde was efficiently prepared via ultrasound irradiation and the template effect of $\mathrm{VO}(\mathrm{acac})_{2}$.

The resulting product was characterized by elemental analysis, infrared, electronic absorption and molar conductance measurement. Single X-Ray structure analysis showed that the complex is a monomeric five-coordinate with a distortedsquare pyramidal geometry. It crystallizes in monoclinic system having unit cell parameters $a=8.3960(5) \AA ; b=12.5533(8) \AA$ and $\mathrm{c}=18.7804(11) \AA ; \alpha=\gamma=90^{\circ} ; \beta=104.843^{\circ}(2)$, with $\mathrm{P} 2{ }_{1} / \mathrm{c}$ space group.

Cyclic voltammetry of the complex, carried out on a glassy carbon (GC) electrode in DMF, showed reversible cyclic voltammograms response in the potential range $0.15-0.60 \mathrm{~V}$ involving a single electron redox wave $\mathrm{V}^{\mathrm{V}} / \mathrm{V}^{\mathrm{IV}}$, the diffusion coefficient is determinedusing GC rotating disk electrode. The Levich plot, $\mathrm{I}_{\text {lim }}=\mathrm{f}\left(\omega^{1 / 2}\right)$, was used to calculate the diffusion-convection controlled currents.

Keywords: Schiff base, Oxovanadium,Ultrasound Irradiation, X-ray Diffraction, Cyclic Voltammetry.

\section{Introduction}

Schiff base ligands (SB) derived from diamines and phenolic aldehydes have proven to be a class of versatile ligands for many transition metals including vanadium(IV)[1-3]. Recently, the coordination chemistry of vanadyl complexes has extraordinary developed in various directions due to their interesting structural features [4-6], catalytic applications [7] potential roles in a variety of biorelated processes, such as insulin mimics [8-9], as well as antimicrobial or anti-leukemia effects [10-11]. The presence of different heterocyclic moieties 
in some oxovanadium SB complexes has been linked to their antitumoral propertiesconfering them a promising future in treatment of cancers [12].

The majority of oxovanadium (IV) SB complexes exhibiting N2O2 coordination and reported in the literature are green. Their structure is generally well established as monomers with five-coordinate square-pyramidal geometry $[5,6]$ but in rare cases, trigonal bipyramidal or distorted octahedral geometries have been observed [13-15]. Heterogeneous oxovanadium SB complexes catalysts, immobilized in microspheres, have been successfully used in the aerobic selective oxidation of ethyl benzene to acetophenone and exhibit high catalytic activity and excellent selectivity [16].

Electrochemicalstudy and structural proprieties of oxovanadium complexes with tetradentate SB ligands attract particular attention because of their reversible one-electron redox behavior [17-18]. However, oxovanadium complexes with a large number of tetradentate SB ligands have been widely reported[19-20].

Electrochemical study and structural properties of oxovanadium complexes bearing tetradentate SB ligands have attracted particular attention owing to their two successive one electron redox couple [17-18] and oxovanadium complexes with a large number of tetradentate SB ligands have been widely reported [19-20]. Over the last decades considerable efforts have been aiming at the development of new synthetic procedures including the solvent-free method [21], microwave assisted synthesis approach [22], electrosynthesis [23] and ultrasound assisted synthesis [24]. Ultrasound irradiation is considered as a green and efficient technique for the activation of reagents in the synthesis of organic [25-26] and inorganic compounds [27]. The formation of several metal complexes bearing azo ligands, like Schiff bases[28-29], porphyrins[30] and quinolones [31], have been enhanced under ultrasound. The significant features of the ultrasound approach are the formation of pure products in prominent yields [32], the improved rate of reactions and the easier handling of reagents and products. The ultrasound synthesis technique is thus highly adapted to green chemistry approaches in coordination chemistry [33].

Considering the importance of oxovanadium SB complexes, we wish to report in this work a safe procedure without solvent under ultrasound irradiation for the synthesis of an oxovanadium complex by template method, previously prepared by F.C. Anson [34] using a conventional procedure. The complex has been characterized by single crystal X-ray diffraction and the electrochemical properties of this complex have been investigated by 
cyclic voltammetry at a glassy carbon (GC) electrode in DMF solvent. The diffusion coefficient has been determined using the Levich plot on a GC rotating disk electrode.

\section{Experimental}

\subsection{Materials and measurements}

All chemical reagents and solvents were purchased from Merck or Aldrich and used without further purification.Sonication was performed on anUS-bathwith frequency of 50-60 $\mathrm{Hz}$ and a nominal power $(720 \mathrm{~W})$.Elemental analyses were performed on an Elementar-Vario EL III CHNS analyzer. Infrared spectra were obtained using potassium bromide (KBr) pellets $\left(4000-400 \mathrm{~cm}^{-1}\right)$ on a Shimadzu FTIR spectrophotometer.Electronic spectra in the 200-900 nm range were recorded using a Shimadzu UV-1800 spectrophotometer using DMF as solvent. Molar conductance of VOL complex was determined in DMF $\left(10^{-3} \mathrm{M}\right)$ at room temperature using MeterLab CDM- 210 conductivity meter.Melting point of the complex was determined on a Kofler Bank 7779 apparatus.

Electrochemical experiments were performed on a PGZ 301 potentiostat, cyclic voltammograms $(\mathrm{CV})$ and rotating disk Electrode (RDE) measurements were recorded at room temperature in DMF solutions containing $0.1 \mathrm{M} \mathrm{LiClO}_{4}$ as supporting electrolyte, using a glassy carbon (GC) as working electrode, platinum wire and a saturated calomel electrode (SCE) were used as counter and reference electrodes, respectively. Prior to the experiments the working electrode was polished and rinsed thoroughly with distilled water and acetone. The polished electrode was placed in $0.5 \mathrm{M} \mathrm{H}_{2} \mathrm{SO}_{4}$ solution and the electrochemical activation of the electrodes were performed by continuous potential cycling from -500 to $1800 \mathrm{mV}$ at a sweep rate of $100 \mathrm{mV} \mathrm{s}^{-1}$ until a stable voltammogram is obtained [35]. Before each electrochemical investigation, the electrolyte was purged with nitrogen during 15 minutes.

Cyclic voltammogram measurements were performed in therange -2200 to $1600 \mathrm{mV}$ versus SCE in which the electrochemical redox couple of $\mathrm{V}^{\mathrm{IV}} / \mathrm{V}^{\mathrm{V}}$ isobserved in the positive window of the scan.Under identical conditions, the ferrocene/ferricinium $\left(\mathrm{Fc} / \mathrm{Fc}^{+}\right)$couple is observed at $455 \mathrm{mV}$.

\subsection{Synthesis procedures}

\subsubsection{Ultrasonication method}

A reaction flask containing $0.344 \mathrm{~g}(2 \mathrm{mmol})$ of 2-hydroxy-1-naphthaldehyde, $66.8 \mu \mathrm{l}(1$ $\mathrm{mmol})$ of 1,2-diaminoethane and $0.265 \mathrm{~g}(1 \mathrm{mmol})$ of bis (acetylacetonato) oxovanadium(Scheme.1), mixed in a mortar, was immersed in an ultrasonic bath at a 
temperature of $50{ }^{\circ} \mathrm{C}$. The reaction mixture was exposed to ultrasound irradiation for $40 \mathrm{~min}$. Upon reaction completion shown by TLC analysis (silica gel, $\mathrm{CH}_{2} \mathrm{Cl}_{2} / \mathrm{MeOH}, 9.5 / 0.5$, V/V). The obtained solid was filtered and washed several times with methanol and diethylether, successively and dried over night in vacuum.Single crystals, suitable for X-ray diffraction, were obtained after 2 days of crystallizationfrom DMSO/MeOH.Color: green, Yield: $95.4 \%$, mp: $>270^{\circ}$.

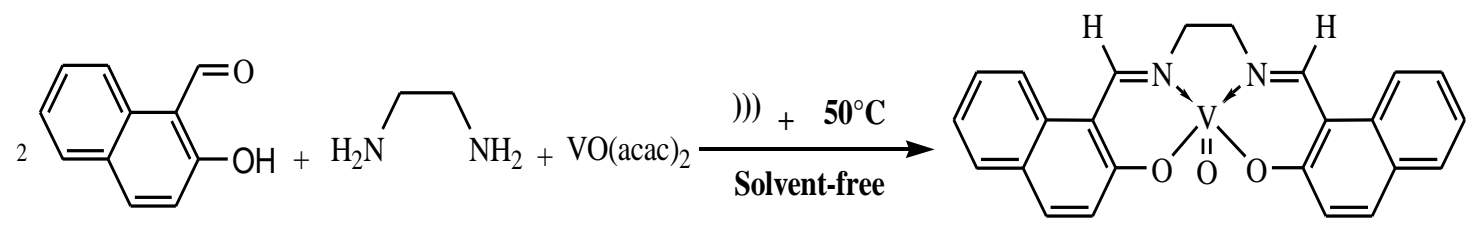

Scheme 1. Synthesis of the oxovanadium complex (VOL).

\subsubsection{Conventional method}

To a solution of $0.344 \mathrm{~g}(2 \mathrm{mmol})$ of 2-hydroxy-1-naphthaldehyde in $8 \mathrm{ml}$ of methanol was added $66.8 \mu \mathrm{l}(1 \mathrm{mmol})$ of 1,2-diaminoethane in $5 \mathrm{ml}$ of methanol.0.265g (1mmol) of bis (acetylacetonato) oxovanadiumdissolved in $15 \mathrm{ml}$ of methanol was added drop wise. The reaction was stirred and refluxed for 3 hours under nitrogen atmosphere. Reaction complete, based on TLC analysis, the resulting compound was filtered and washed with methanol and diethylether to afford pure desired product yielding 77.6\%.S.A. Amer [36], N. Choudhary [37] and F.C. Anson [34-38] have reported the synthesis of this complex yielding70-90\%.

Both oxovanadium complexes gave satisfactory elemental analysis, in good agreement with calculated values. Analysis calculated for $\mathrm{C}_{24} \mathrm{H}_{18} \mathrm{~N}_{2} \mathrm{O}_{3} \mathrm{~V}$, prepared under ultrasound irradiation: C: $66.52 \%, \mathrm{H}: 4.19 \%, \mathrm{~N}: 6.46 \%$; found: C: $66.83 \%$; H:4.35\%; N: $6.32 \%$; IR $\left(\mathrm{KBr}\right.$ pellets $\left.\vee \mathrm{cm}^{-1}\right) 1618(\mathrm{C}=\mathrm{N}), 1340-1360(\mathrm{C}-\mathrm{O}), 1542(\mathrm{C}=\mathrm{C}), 983(\mathrm{~V}=\mathrm{O})$; UV-Vis: $\mathrm{DMF}, \lambda$ $\mathrm{nm},\left[\varepsilon \mathrm{M}^{-1} \mathrm{~cm}^{-1}\right]: 323[7722], 380[4166], 610$ [83].

\subsection{X-ray crystallography}

Suitable single crystals of the oxovanadium complex (VOL)were grown by slow layer diffusion of DMSO into a MeOH solution at room temperature. A green plate single crystal of dimensions $0.25 \mathrm{x} \quad 0.18 \mathrm{x} 0.12 \mathrm{~mm}^{3}$ suitable for X-ray analysis was used for data collection at 173(2) K on a Bruker APEX II DUO Kappa-CCD diffractometer equipped with an Oxford Cryosystem liquid device, using Mo/K $\alpha$ radiation $(\alpha=0.71073 \AA)$. The crystal-detector distance was $38 \mathrm{~mm}$.

The cell parameters were determined (APEX2 software) [39] from reflections taken from three sets of 12 frames, each at 10s exposure. The structure was solved by direct 
methods using the program SHELXS-97 [40]. The refinement and all further calculations were carried out using SHELXL-2013 [41]. The H-atoms were included in calculated positions and treated as riding atoms using SHELXL default parameters. The non-H atoms were refined anisotropically, using weighted full-matrix least-squares on $\mathrm{F}^{2}$. A semi-empirical absorption correction was applied using SADABS in APEX2 [39]; transmission factors: $\operatorname{Tmin} / \mathrm{Tmax}=0.6157 / 0.7456$.

\subsection{Results and discussion}

\subsubsection{Molar Conductance}

The molar conductance of $10^{-3} \mathrm{M}$ of VOLcomplex in DMF as solvent is $\Lambda=1.74 \Omega^{-1}$ $\mathrm{cm}^{2} \mathrm{~mol}^{-1}$, this very low value indicating that the title complex is electritically neutral[42-43].

\subsubsection{Crystal structure of VOLcomplex}

The crystal structure of the complex, depicted in Fig. 1, consists of one molecule in the asymmetric unit. The compound crystallizes in the monoclinic system with space group $\mathrm{P} 21 / \mathrm{c}$ and the cell dimensions $\mathrm{a}=8.3960$ (5); $\mathrm{b}=12.5533$ (8); $\mathrm{c}=18.7804$ (11) $\AA$; $\alpha=\gamma=90^{\circ}$; $\beta=104.843^{\circ}(2)$.

\section{Fig. 1.}

Parameters for data collection and refinement are summarized in Table 1. Selected bond lengths and angles are listed in Table 2.

Table 1

Table 2

The structure of the VOL complex has a slightly distorted square pyramidal coordination geometry.The basal square plane is formed by the N,N'-bis (2-hydroxy-naphthalidenato)diaminoethane molecule, which acts as a tetradentate ligand through its two $\mathrm{N}$ atoms and two deprotonated phenol $\mathrm{O}$ atoms. The two naphthalene rings are nearly coplanar with a dihedral angle of $2.315(41)^{\circ}$ between the two rings. Typical values of $\mathrm{V}-\mathrm{N}$ bond distances of 2.0367(16) and 2.0401(16) $\AA$, and V-O bond distances of 1.9491(14) and 1.9324(14) $\AA$, are found in agreement with those reported for other oxovanadium (IV) complex [44]. The V1O3 bond distance is $1.5951(14) \AA$ and the V1 atom is located $0.596 \AA$ above the mean plane defined by atoms $\mathrm{N} 1 / \mathrm{N} 2 / \mathrm{O} 1 / \mathrm{O} 2$. In the cell, the crystal is stabilized by a network of 
intermolecular hydrogen bonds, which are shown in Fig. 2. In these circumstances, there are no other intramolecular interactions in the structure.

\section{Fig. 2.}

\subsubsection{FTIR spectra}

The IR spectrum of the VOL complex exhibits several prominent bands in the 4000$400 \mathrm{~cm}^{-1}$ region. Among these absorptions, the VOL complex displayed strong $\mathrm{C}=\mathrm{N}$ stretch (around $1618 \mathrm{~cm}^{-1}$ ) which indicates the $\mathrm{C}=\mathrm{N}$ group of the coordinated SB ligand[45]. It can be noticed that $v \mathrm{C}=\mathrm{N}$ band in the complex is shifted to the lower energy region of approximately $20 \mathrm{~cm}^{-1}$ in the corresponding free ligand reported in the literature [46-47]. Another broad band around $1540 \mathrm{~cm}^{-1}$ is related to the aromatic $\mathrm{C}=\mathrm{C}$ vibration [1]. In addition, the stretching vibration of $\mathrm{C}-\mathrm{O}$, in the naphtholatemoities, at $1340-1360 \mathrm{~cm}^{-1}$ suggests the coordination of the naphtholate oxygen to the vanadium ion as reported in the literature[46], this absorption frequency is higher than that observed in the spectrum of corresponding ligand $\left(1327 \mathrm{~cm}^{-1}\right)$ [48-49].

The complex exhibits characteristic sharp and medium $v(\mathrm{~V}=\mathrm{O})$ at $987 \mathrm{~cm}^{-1}$ indicating that there is no intermolecular interaction with the participation of the oxovanadium moiety [2-10].

\subsubsection{Electronic spectroscopy}

The electronic spectrum of the oxovanadium complex was recorded using DMF solution at room temperature in the range 200-800 $\mathrm{nm}$. The complex showed two intense bands at 323 and $380 \mathrm{~nm}$ that can be assigned to $\pi \rightarrow \pi^{*}$ transitions of the aromatic rings of naphthalene and $n \rightarrow \pi^{*}$ transitions of the azomethine chromophores respectively [50]. A broad shoulder is observed near $400 \mathrm{~nm}$ corresponding to the ligand-to-metal charge-transfer transition (LMCT), from thelone pair system of both O-atoms in naphthalene rings to the $\mathrm{d}$ orbital of the vanadium atom [19].The vanadium (IV) complex exhibits an additional low intensity broad band in the range of $550-800 \mathrm{~nm}$ due to $\mathrm{d} \rightarrow \mathrm{d}$ transitions [5]. The UV-vis absorption spectrum of VOL complex is shown in Fig. 3.

\section{Fig.3.}

\subsubsection{Electrochemical}


The redox properties of the SB ligand and its oxovanadium complex were investigated by cyclic voltammetry under nitrogen atmosphere, using DMF solution containing $0.1 \mathrm{M}$ $\mathrm{LiClO}_{4}$ as supporting electrolyte, at a glassy carbon as a working electrode, the redox potentials are expressed with reference to SCE. The cyclic voltammograms are given in Fig. 4.

\section{Fig. 4.}

The cyclic voltammogram of the VOL complex showed three anodic waves at $\mathrm{E}_{\mathrm{pa}}=+1125, \mathrm{E}_{\mathrm{pa}}^{1}=+415$ and $\mathrm{E}_{\mathrm{pa}}^{2}=-1659 \mathrm{mV} / \mathrm{SCE}$. The firstanodic waveisirreversible andassigned to the oxidation of the ligand[19]. The second and the third onesarequasireversibleredox systems showing the half wave potentials at $E_{1 / 2}^{1}=+374$ and $E_{1 / 2}^{2}=-1704 \mathrm{mV} /$ SCE. Thepeak-to-peak separation between the anodic and the cathodic potentials, $\Delta \mathrm{E}_{\mathrm{p}}^{1}$ and $\Delta \mathrm{E}_{\mathrm{p}}^{2}$, are of 82 and $90 \mathrm{mVrespectively} \mathrm{[51-52]} \mathrm{at} 100 \mathrm{mVs}^{-1}$ scan rate. The half wave potentials $\mathrm{E}_{1 / 2}^{1}=+374$ and $\mathrm{E}_{1 / 2}^{2}=-1704 \mathrm{mV} / \mathrm{SCE}$ are assigned to the $\mathrm{VO}^{\mathrm{V}} / \mathrm{VO}^{\mathrm{IV}}$ and $\mathrm{VO}^{\mathrm{IV}} / \mathrm{VO}^{\mathrm{III}}$ redox processes, similar compounds are widely reported in the literature.[17, 5354].The reduction wave occurred at $\mathrm{E}_{\mathrm{pc}}=-1537 \mathrm{mV} / \mathrm{SCE}$ is due to the reduction of the azomethine groups. [55]

In the free ligand, two irreversible waves are observed on its cyclic voltammogram, an anodic wave appearing at $+1116 \mathrm{mV} / \mathrm{SCE}$ and a cathodic one at $-1653 \mathrm{mV} / \mathrm{SCE}$ attributed respectively to the oxidation of the hydroxyl functionsand the reduction of the azomethine groups as reported in the literature [56,57]. The oxidation and the reduction peak potentials of the ligand are shifted to a slightly lower potential values, reveals that the hydroxyl(-OH) and the azomethine $(\mathrm{C}=\mathrm{N})$ groups are involved in the binding of the vanadyl core. [58]

\section{Table 3}

Cyclic voltammogram measurements at different scan rates, between 50 and $400 \mathrm{mVs}^{-1}$ (Fig. 5) indicate, in the potential range of $150-600 \mathrm{mV} / \mathrm{SCE}$, that $\mathrm{E}_{\mathrm{p}}$ values are slightly dependent upon the scan rate. By increasing the scan rate values, the anodic and the cathodic peak potentials shift respectively to a more positive andamore negativevalues. The ratios of the anodic to cathodic peaki $\mathrm{p}_{\mathrm{p}} / \mathrm{i}_{\mathrm{pc}}$ currents are close to unity(Table 3$)$. The peak separation between the cathodic and the anodic peak potentials, $\Delta \mathrm{E}_{\mathrm{p}}$, have beendetermined, and reach a value of $82 \mathrm{mV}$ at $100 \mathrm{mVs}^{-1}$ scan rate that is greater than that expected for reversible systems, which indicates a quasi-reversible electrode process. Similar results have been reported for several oxovanadium SB complexes [12,17].A linear relationship between the anodic peak 
current and the square root of the scan rates $\left(i_{p a}=f\left(v^{1 / 2}\right)\right)$ is observed (inset of Fig.5), this fact implies that this electrochemical process is mainly diffusion-controlled $[6,59]$.

Fig. 5.

In order to determine the diffusion coefficient, a hydrodynamic voltammetry experiment is carried outusinga glassy carbon rotating disk electrode (RDE) at various rotation rates, from 250 to $3000 \mathrm{rpm}$. The experiment is realized in DMF solution containing $1 \mathrm{mmol}$ of VOL complex and $0.1 \mathrm{M} \mathrm{LiClO}_{4}$. The current-potential curves and the Levich plotsare shownare in Fig. 6. Under the studied conditions, a linear correlation between the limiting current and the square root of the rotating rate is observed which leads to the determination of the value of the proportionality constant in the Levich equation for a one electron $\mathrm{VO}^{\mathrm{V}} / \mathrm{VO}^{\mathrm{IV}}$ reduction [60]. Diffusion coefficient was calculated to be $\left(2.7 .10^{-6} \mathrm{~cm}^{2} / \mathrm{s}\right)$ from the slopes of the $i_{\text {lim }} \mathrm{vs} . \omega^{1 / 2}$ plots, using Levich equation [61]:

$$
\mathrm{i}_{\lim }=0.620 \mathrm{nFAD}^{\frac{2}{3}} \omega^{\frac{1}{2}} v^{\frac{-1}{6}} \mathrm{C}
$$

where $\mathrm{i}_{\text {lim }}$ is the Levich current $\left(\mu \mathrm{A} / \mathrm{cm}^{2}\right), \mathrm{n}$ is the number of electrons transferred, $\mathrm{F}$ is the faraday constant $(\mathrm{C} / \mathrm{mol}), \mathrm{A}$ is the electrode area $\left(\mathrm{cm}^{2}\right), v$ is the kinematic viscosity $\left(\mathrm{cm}^{2} / \mathrm{s}\right), \mathrm{D}$ and $\mathrm{C}$ are the diffusion coefficient $\left(\mathrm{m}^{2} / \mathrm{s}\right)$ and the analyte concentration $\left(\mathrm{mol} / \mathrm{cm}^{3}\right)$ respectively, $\omega$ is the angular rotation rate of the electrode $(\mathrm{rad} / \mathrm{s})$.

Fig. 6.

\section{Conclusion}

In this paper, we describe the sonochemical and conventional synthesis ofa symmetrical oxovanadium Schiff basecomplex. In free solvent conditions, the ultrasonic irradiation procedure reduces the reaction time to 40 minutes instead of 3 hours compared with the conventional method and affords the desired product in a higher yield and purity. The non-electrolytic nature of the VOL complex was confirmed on the basis of their molar conductance value.The crystallographic data showed that the vanadium (IV) ion in VOL Schiff base complex is five coordinated with distorted square-pyramid geometry.

The electrochemical behavior of the complex exhibitsa quasi-reversible one electron redox process at $\mathrm{E}_{1 / 2}=374 \mathrm{mV} / \mathrm{SCE}$, with current ratio $\mathrm{i}_{\mathrm{pa}} / \mathrm{i}_{\mathrm{pc}}$ equals to unity and the peak-topeak separation value, $\Delta \mathrm{E}_{\mathrm{p}}$, is of $82 \mathrm{mV}$. The linear relationship observed between the anodic peak current $\left(\mathrm{i}_{\mathrm{pa}}\right)$ and the square root of the scan rates $\left(\mathrm{v}^{1 / 2}\right)$ indicates a diffusion-controlled 
nature of the electrode process. The diffusion coefficient is $2.5 .10^{-6} \mathrm{~cm}^{2} / \mathrm{s}$ from the Levich plots, $\mathrm{I}_{\lim }=\mathrm{f}\left(\omega^{1 / 2}\right)$.

\section{Supplementary data}

CCDC 1003714contains the supplementary crystallographic data for VOL. These data can be obtained free of charge via http://www.ccdc.cam.ac.uk/conts/retrieving.html, or from the Cambridge Crystallographic Data Centre, 12 Union Road, Cambridge CB2 1EZ, UK; fax: (+44) 1223-336-033; or e-mail: deposit@ccdc.cam.ac.uk.

\section{Acknowledgements}

The Authors gratefully acknowledge the financial support from The Algerian Ministry of Higher Education and Scientific Research. They also acknowledge the help to access the NMR Facility and Microanalysis Service at the Chemistry Institute of the University of Strasbourg - France.

\section{References}

[1] M. Asadi, Z. Asadi, N. Savaripoor, M. Dusek, V. Eigner, M.R. Shorkaei, M. Sedaghat, Spectrochim. Acta, Part A 136 (2015) 625-634.

[2] K. Mohammadi, S.S. Azad, A. Amoozegar, Spectrochim. Acta, Part A 146 (2015) 221227.

[3] G. von Willingh, H.S. Abbo, S.J.J. Titinchi, Catal. Today 227 (2014) 96-104.

[4] D. Qu, F. Niu, X. Zhao, K.-X. Yan, Y.-T. Ye, J. Wang, M. Zhang, Z. You, Bioorg. Med. Chem. 23 (2015) 1944-1949.

[5] P. Paciorek, J. Szklarzewicz, A. Jasinska, B. Trzewik, W. Nitek, M. Hodorowicz, Polyhedron 87 (2015) 226-232.

[6] H. Hosseini-Monfared, R. Bikas, P. Mahboubi-Anarjan, A.J. Blake, V. Lippolis, N.B. Arslan, C. Kazak, Polyhedron 69 (2014) 90-102.

[7] G. Grivani, V. Tahmasebi, A. D. Khalaji, Polyhedron 68 (2014) 144-150.

[8] A. A. Nejo, G. A. Kolawole, A. R. Opoku, J. Wolowska, P. O’Brien, Inorg. Chim. Acta 362 (2009) 3993-4001.

[9] M.L. Sharma, S.K. Sengupta, O.P. Pandey, Spectrochim. Acta, Part A 95 (2012) 562-568. 
[10] Z. H. Chohan, S. H. Sumrra, M. H. Youssoufi, T. B. Hadda, Eur. J. Med. Chem. 45 (2010) 2739-2747.

[11] A. Meshkini, R. Yazdanparast, Exp. Mol. Pathol, 89 (2010) 334-342.

[12] I.E. León, N. Butenko, A.L. Di Virgilio, C.I.Muglia, E.J. Baran, I. Cavaco, S.B. Etcheverry, J. Inorg. Biochem. 134 (2014) 106-117.

[13] S. Liang, D. V. Derveer, S. Y. Qian, B. Sturgeon, X. R. Bu, Polyhedron 21 (2002) 2021 2025 .

[14] G. Grivani, S. Delkhosh, K. Fejfarová, M. Dušek, A.D. Khalaji, Inorg. Chem. Commun. 27 (2013) 82-87.

[15] G. Grivani, A. Ghavami, M. Kucerakova, M. Dušek, A.D. Khalaji, J. Mol. Struct. 1076 (2014) 326-332.

[16] B. Gao, Y. Li, N. Shi, React. Funct. Polym. 73 (2013) 1573-1579.

[17] P. Galloni, A. Coletti, B. Floris, V. Conte, Inorg. Chim. Acta 420 (2014) 144-148.

[18] S. Rayati, F. Ashouri, C. R. Chim. 15 (2012) 679-687.

[19] V. T. Kasumov, F. Koksal, M. Aslanoglu, Y. Yerli, Spectrochim. Acta, Part A 77 (2010) 630-637.

[20] K. Mohammadi, M. Rastegari, Spectrochim. Acta, Part A 97 (2012) 711-716.

[21] G.T. Tigineh, Y.-S. Wen, L.-K. Liu, Tetrahedron 71 (2015) 170-175.

[22] M. Yadav, N. Mishra, N. Sharma, S. Chandra, D. Kumar, Spectrochim. Acta, Part A 132 (2014) 733-742.

[23] S. Meghdadi, V. Mirkhani, R. Kia, M. Moghadam, S. Tangestaninejad, I. M.-Baltork, Polyhedron 85 (2015) 519-524.

[24] H. Ghasempour, A. Azhdari Tehrani, A. Morsali, Ultrason. Sonochem. 27 (2015) 503508.

[25] H.B. Ammar, M. Chtourou, M. H. Frikha, M. Trabelsi, Ultrason. Sonochem. 22 (2015) $559-564$.

[26] Y.-L. Song, Y.-F. Dong, F. Wu, T. Yang, G.-L. Yang, Ultrason. Sonochem. 22 (2015) $119-124$.

[27] S. Anandan, T. Sivasankar, T. L-Villarreal, Ultrason. Sonochem. 21 (2014) 1964-1968. 
[28] S. Rayati, P. Abdolalian, Appl. Catal., A 456 (2013) 240- 248.

[29] M. Montazerozohori, S.M. Jahromi, A. Naghiha, J. Ind. Eng. Chem. 22 (2015) 248-257.

[30] C. Sun, B. Hu, W. Zhou, S. Xu, Z. Liu, Ultrason. Sonochem.18 (2011) 501-505.

[31] A. Shahrjerdi, S.S.H. Davarani, E. Najafi, M.M. Amini, Ultrason. Sonochem. 22 (2015) 382-390.

[32] J. S-Ghomi, R. Masoomi, Ultrason. Sonochem. 23 (2015) 212-218.

[33] P.N. Kalaria, S.P. Satasia, J.R. Avalani, D.K. Raval, Eur. J. Med. Chem.83 (2014) 655664.

[34] Z. Liu, F.C. Anson, Inorg. Chem. 40 (2001) 1329-1333.

[35] M. Shamsipur, A. Salimi, H. Haddadzadeh, M.F. Mousavi, J. Electroanal. Chem.517 (2001) 37-44.

[36] S.A. Amer, M. Gaber, R. M. ISSA, Polyhedron 7-24 (1988) 2635-2640.

[37] N. Choudhary, D. L. Hughes, U. Kleinkes, L.F. Larkworthy, G. J. Leigh, M. Maiwald, C. J. Marmion, J. R. Sanders, G. W. Smith, C,Sudbrake, Polyhedron 16- 9 (1997) 1517-1528.

[38] Z. Liu, F.C. Anson,J. Mol. Catal. A: Chem.186 (2002) 43-51.

[39] “M86-E01078 APEX2 User Manual”, Bruker AXS Inc., Madison, USA, 2006.

[40] G. M. Sheldrick, SHELXS-97. Program for Crystal Structure Determination, ActaCrystallogr., A46 (1990), 467-473.

[41] G.M. Sheldrick, (2008) “A short history of SHELX”, Acta.Cryst., A64, 112-122.

[42] Z.-L. You, D.-H. Shi, J.-C. Zhang, Y.-P. Ma, C. Wang, K. Li, Inorg. Chim. Acta 384 (2012) 54-61.

[43] B.T. Thaker, R.S. Barvalia, Spectrochim. Acta, Part A 84 (2011) 51-61.

[44] M.-G. Xie, L. Li, X.-D. Yang, W.-P. Liu, S.-P. Yan, Y.-F. Niu, Z.-H Meng, Eur. J. Med. Chem. 45 (2010) 2327-2335.

[45] K. Ouari, S. Bendia, J. Weiss, C. Bailly, Spectrochim. Acta, Part A 135 (2015) 624-631.

[46] K. N. Kumar, R. Ramesh, Polyhedron 24 (2005) 1885-1892.

[47] Y. Choia, W. Kim, K. Chung, M. Chung, H. Nam, Microchem. J. 65 (2000) 3-15.

[48] C. R. Bhattacharjee, P. Goswami, P. Mondal, Inorg. Chim. Acta 387 (2012) 86-92. 
[49] M. Bagherzadeh, M. Amini, J. Coord. Chem. 63 (2010), 3849-3858.

[50] A.M. Ajlouni, Z.A. Taha, W. Momani, A.K. Hijazi, M. Ebqa'ai, Inorg. Chim. Acta 388 (2012) 120-126.

[51] P.K. Sasmal, A.K. Patra, A.R. Chakravarty, J. Inorg. Biochem. 102 (2008) 1463-1472.

[52] M. Sutradhar, T.R. Barman, S. Ghosh, M.G.B. Drew, J. Mol. Struct. 1037 (2013) 276282.

[53] P. Prasad, P. K. Sasmal, R. Majumdar, R.R. Dighe, A.R. Chakravarty, Inorg. Chim. Acta 363 (2010) 2743-2751.

[54] V. Prakash, K. Srivastava, J. Prasad, J. Mol. Liq. 204 (2015) 1-9.

[55] M. Sarigul, P. Deveci, M. Kose, U. Arslan, H.T. Dagi, M.Kurtoglu, J. Mol. Struct. 1096 (2015) 64-73.

[56] I. Kaya, E. Bora, A. Aydin, Prog. Org. Coat. 77 (2014) 463- 472.

[57] H. Temel, S. Pasa, Y.S. Ocak, I. Yilmaz, S. Demir, I. Ozdemir, Synth. Met. 161 (2012) $2765-27$.

[58] E. S. Bazhina, M. E. Nikiforova, G. G. Aleksandrov, N. N. Efimov, H. A. Ugolkova, O. M. Nikitin, T. V. Magdesieva, A. S. Bogomyakov, V. V. Minin, A. A. Sidorov, V. M. Novotortsev, I. L. Eremenko, Inorg. Chim. Acta 392 (2012) 192-198.

[59] K. K. Raja, L. Lekha, R. Hariharan, D. Easwaramoorthi, G. Rajagopal, J. Mol. Struct. 1075 (2014) 227-233.

[60] S. Gutierrez-Granados, F. Bedioui, J. Devynck, Electrochim. Acta 38 (1993) 1747-1751.

[61] A.J. Bard, L.R. Faulkner, Electrochemical Methods: Fundamentals and Applications, Second ed., Wiley, New York, 2001. 


\section{Captions}

Fig. 1. ORTEP plot of the X-ray crystal structure of VOL complex with atom labeling scheme. Displacement ellipsoids are drawn at the $50 \%$ probability level except for the $\mathrm{H}$ atoms, which are shown as circles of arbitrary radius.

Fig. 2. Crystal packing of VOL complex showing intermolecular hydrogen bonds as dashed lines.

Fig. 3. UV-vis absorption spectra of VOL complex in DMF at room temperature, the inset shows an expanded spectrum between 450 and $800 \mathrm{~nm}$.

Fig. 4. Cyclic voltammograms of VOL complex (a), SB ligand (b) and $\mathrm{Fc} / \mathrm{Fc}^{+}(\mathrm{c})$ in $0.1 \mathrm{M}$ $\mathrm{LiClO}_{4} / \mathrm{DMF}$ solution at scan rate of $100 \mathrm{mVs}^{-1}$.

Fig. 5. Cyclic voltammograms of VOL complex in $0.1 \mathrm{M} \mathrm{LiClO}_{4} / \mathrm{DMF}$ solution at various scan rates: from inner to outer, 50, 100, 150, 200, 250, 300, 350 and $400\left(\mathrm{mVs}^{-1}\right)$ respectively. The inset shows the anodic currents vs $\mathrm{v}^{1 / 2}$.

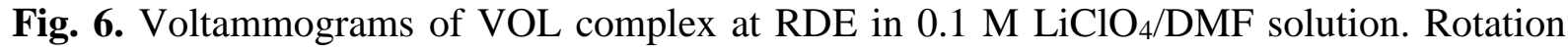
rates: from 250 to $3000 \mathrm{rpm}$. The inset shows the Levich plot. 


\section{Table 1}

Crystallographic and refinement data of VOLcomplex

\begin{tabular}{|c|c|}
\hline Compound & VOL \\
\hline Molecular formula moiety & $\mathrm{C}_{24} \mathrm{H}_{18} \mathrm{~N}_{2} \mathrm{O}_{3} \mathrm{~V}$ \\
\hline Molecular weight & 433.34 \\
\hline Temperature (K) & $173(2)$ \\
\hline Radiation & Mo $\mathrm{K}_{\alpha} 0.71073 \AA$ \\
\hline Crystal system & Monoclinic \\
\hline Space group & $\mathrm{P} 2{ }_{1} / \mathrm{C}$ \\
\hline $\mathrm{a} / \AA$ & $8.3960(5)$ \\
\hline $\mathrm{b} / \AA$ & $12.5533(8)$ \\
\hline c/ $\AA$ & $18.7804(11)$ \\
\hline Alpha & 90.00 \\
\hline Beta & $104.843(2)$ \\
\hline Gamma & 90.00 \\
\hline $\mathrm{V} / \AA^{3}$ & $1913.4(2)$ \\
\hline $\mathrm{Z}$ & 4 \\
\hline$D_{\text {calc }}\left(\mathrm{g} \cdot \mathrm{cm}^{-3}\right)$ & 1.504 \\
\hline Crystal size $\left(\mathrm{mm}^{3}\right)$ & $0.25,0.18,0.12$ \\
\hline Crystal color & Green \\
\hline Crystal description & Plate \\
\hline Absorption coefficient & 0.549 \\
\hline $\mathrm{F}(000)$ & 892 \\
\hline Reflections collected/unique & $19012 / 4639\left[\mathrm{R}_{\mathrm{int}}=0.0526\right]$ \\
\hline Ranges/ indices $(\mathrm{h} ; \mathrm{k} ; \mathrm{l})$ & $-11,11 ;-16,16 ;-24,24$ \\
\hline Tetalimit & $1.972-28.110$ \\
\hline No. of observed data $[\mathrm{I}>2 \sigma(\mathrm{I})]$ & 3296 \\
\hline No. of parameters & 271 \\
\hline No. of restraints & 0 \\
\hline Goodness-of-fit on $\mathrm{F}^{2}$ & 1.011 \\
\hline Largest diff, peak and hole $\left(\mathrm{e} \AA^{-3}\right)$ & 0.512 and -0.317 \\
\hline $\mathrm{R}_{1}, \mathrm{wR}_{2}[\mathrm{I} \geq 2 \sigma(\mathrm{I})]^{\mathrm{a}}$ & $0.0699,0.0930$ \\
\hline $\mathrm{R}_{1}, \mathrm{wR}_{2}$ (all data) ${ }^{\mathrm{a}}$ & $0.0384,0.0828$ \\
\hline
\end{tabular}




\section{Table 2}

Selected bond lenghts $(\AA)$, and bond angles $\left(^{\circ}\right)$ for $\mathrm{VOL}^{\text {et }}$ complex.

\begin{tabular}{llllll}
\hline Bond lenghts $(\stackrel{\AA}{\mathbf{A}})$ & \multicolumn{3}{l}{ Bond angles $\left(^{\circ}\right)$} \\
\hline V1-N1 & $2.0367(16)$ & O1-V1-O2 & $89.21(6)$ & O1-V1-O3 & $107.09(7)$ \\
V1-O1 & $1.9491(14)$ & O1-V1-N1 & $85.41(6)$ & O1-V1-N2 & $148.88(6)$ \\
V1-O3 & $1.5951(14)$ & O2-V1-O3 & $111.75(7)$ & O2-V1-N1 & $140.29(6)$ \\
V1-N2 & $2.0401(16)$ & O2-V1-N2 & $85.83(6)$ & O3-V1-N1 & $107.42(7)$ \\
V1-O2 & $1.9324(14)$ & O3-V1-N2 & $103.27(7)$ & N1-V1-N2 & $79.12(6)$ \\
\hline
\end{tabular}

\section{Table 3}

Cyclic voltammetric parameters for the oxovanadium SB complex in different scan rates

\begin{tabular}{|c|c|c|c|c|c|c|c|}
\hline $\begin{array}{c}\mathbf{v} \\
\left(\mathrm{mVs}^{-1}\right)\end{array}$ & $\begin{array}{c}\mathbf{E}_{\mathbf{p a}} \\
(\mathrm{mV} / \mathrm{SCE})\end{array}$ & $\begin{array}{c}\mathbf{E}_{\mathbf{p c}} \\
(\mathrm{mV} / \mathrm{SCE})\end{array}$ & $\begin{array}{r}\Delta \mathbf{E}_{\mathbf{p}} \\
(\mathrm{mV})\end{array}$ & $\begin{array}{c}\mathbf{E}_{\mathbf{1} / \mathbf{2}} \\
(\mathrm{mV} / \mathrm{SCE})\end{array}$ & $\begin{array}{c}\mathbf{i}_{\mathbf{p a}} \\
(\mathrm{mA})\end{array}$ & $\begin{array}{c}\mathbf{i}_{\mathbf{p c}} \\
(\mathrm{mA})\end{array}$ & $\begin{array}{c}\mathbf{i}_{\mathbf{p a}} / \mathbf{i}_{\mathbf{p c}} \\
/\end{array}$ \\
\hline 50 & 415 & 335 & 80 & 375 & 10.33 & 10.13 & 1.01 \\
\hline 100 & 415 & 333 & 82 & 374 & 14.66 & 14.35 & 1.02 \\
\hline 150 & 417 & 335 & 82 & 376 & 18.11 & 17.2 & 1.05 \\
\hline 200 & 418 & 334 & 84 & 376 & 20.54 & 19.56 & 1.05 \\
\hline 250 & 420 & 334 & 86 & 377 & 22.79 & 22.49 & 1.01 \\
\hline 300 & 422 & 332 & 90 & 377 & 25.35 & 25.22 & 1.01 \\
\hline 350 & 423 & 331 & 92 & 377 & 26.56 & 25.79 & 1.03 \\
\hline 400 & 424 & 330 & 94 & 377 & 28.24 & 27.76 & 1.02 \\
\hline
\end{tabular}

